\title{
REFLEXÕES SOBRE DISTANCIAMENTO, ISOLAMENTO SOCIAL E QUARENTENA COMO MEDIDAS PREVENTIVAS DA COVID-19
}

\author{
REFLECTIONS ON DISTANCING, SOCIAL ISOLATION AND QUARANTINE AS PREVENTIVE MEASURES AGAINST \\ COVID-19
}

\section{REFLEXIONES SOBRE DISTANCIAMIENTO, AISLAMIENTO SOCIAL $Y$ CUARENTENA COMO MEDIDAS PREVENTIVAS DE LA COVID-19}

Joana Angélica Andrade Diass, Mauricio Fagner Santos Lima Dias ${ }^{2}$, Zulmerinda Meira Oliveira ${ }^{3}$, Livia Maria Andrade de Freitas ${ }^{4}$, Nilton Cesar Nogueira Santos ${ }^{5}$, Maria da Conceição Andrade Freitas ${ }^{6}$

\section{RESUMO}

Objetivo: Refletir sobre distanciamento, isolamento social e quarentena como medidas de prevenção da infecção em massa pelo SARSCoV-2, vírus responsável pela COVID-19. Métodos: Ensaio teórico reflexivo, embasado em ideias de estudiosos do tema, mediante levantamento bibliográfico no Google Acadêmico, na PUBMED/MEDLINE, em site oficial e jornais online, selecionados a partir das palavras-chave "COVID-19", "distanciamento social", "isolamento social”, "quarentena" e suas combinações. Resultados e Discussão: Distanciamento, isolamento social e quarentena são medidas preventivas de extrema importância para a redução da velocidade e a disseminação da infecção entre indivíduos. Além de frear a mortalidade causada pela doença, envolvem aspectos de natureza emocional, psicológica, biológica, social, cultural, política e espiritual. Requer utilização de estratégias de enfrentamento, como mudanças no estilo de vida, manter boas relações interpessoais online, afastar-se do excesso de informações sobre a doença, realizar atividades de lazer, exercer a solidariedade, entre outros. Conclusão: Embora essas medidas preventivas acarretem prejuízos à economia mundial, às relações governamentais e de trabalho, mostram-se como grande oportunidade de a sociedade vir a ter uma melhor compreensão da vida em coletividade, dos estados ressignificarem as suas práticas e, ainda, das pessoas reavaliarem o que é mesmo importante em suas vidas.

Descritores: Isolamento social; Infecções por Coronavírus; Pandemias; Prevenção de Doenças; Quarentena.

\begin{abstract}
Objective: To reflect on distancing, social isolation and quarantine, as measures to prevent mass infection by SARS-CoV-2, the virus responsible for COVID-19. Methods: Reflective theoretical essay, based on ideas of scholars on the subject, by means of a bibliographic survey on Google Scholar, PUBMED/MEDLINE, official websites and online newspapers, selected from the keywords "COVID-19", "social distancing", "social isolation", "quarantine" and their combinations. Results and Discussion: Distancing, social isolation and quarantine are extremely important preventive measures to reduce the speed and spread of the infection among individuals. In addition to curbing the disease mortality levels, they involve aspects of an emotional, psychological, biological, social, cultural, political, and spiritual nature. They require the use of coping strategies, such as changes in lifestyle, maintenance of good interpersonal relationships online, avoidance of excess of information about the disease, performance of leisure activities, exercise of solidarity, among others. Conclusion: Although these preventive measures harm the world's economic, governmental and labor relations, they are a great opportunity for society to better understand collective life; for nations to reframe their practices; and for people to reevaluate what is really important in their lives.
\end{abstract}

Descriptors: Social isolation; Coronavirus infections; Pandemics; Disease Prevention; Quarantine.

\section{RESUMEN}

Objetivo: Reflexionar sobre distanciamiento, aislamiento social y cuarentena, como medidas de prevención de la infección en masa por el SARS-CoV-2, virus responsable por la COVID-19. Métodos: Ensayo teórico reflexivo, basado en ideas de estudiosos del tema, mediante un levantamiento bibliográfico en Google Académico, en PUBMED/MEDLINE, páginas oficiales y periódicos online, seleccionados a partir de las palabras clave "COVID-19", "distanciamiento social", "aislamiento social", "cuarentena" y sus combinaciones. Resultados y Discusión: El distanciamiento, el aislamiento social y la cuarentena son medidas preventivas de extrema importancia para la reducción de la velocidad y diseminación de la infección de los individuos. Además de frenar la mortalidad por la enfermedad, implican aspectos de naturaleza emocional, psicológica, biológica, social, cultural, política y espiritual. Requiere la utilización de estrategias de enfrentamiento, como cambios en el estilo de vida, mantener buenas relaciones interpersonales online, alejarse del exceso de informaciones sobre la enfermedad, realizar actividades de ocio, ejercer la solidaridad, entre otros. Conclusión: Aunque esas medidas preventivas acarreten perjuicios a la economía mundial, a las relaciones gubernamentales y de trabajo, se muestran como una gran oportunidad para que la sociedad venga a tener una mejor comprensión de la vida en colectividad, que los estados resignifiquen sus prácticas y que las personas reevalúen lo que es realmente importante en sus vidas.

Descriptores: Aislamiento social; Infecciones por Coronavirus; Pandemias; Prevención de Enfermedades; Cuarentena.

${ }^{1}$ Enfermeira. Professora Adjunto da Universidade Estadual do Sudoeste da Bahia-UESB. ${ }^{2}$ Médico da Família da Prefeitura Municipal de Vitória da Conquista/Bahia. ${ }^{3}$ Enfermeira. Professora Adjunto da UESB. ${ }^{4}$ Cirurgiã-Dentista. Professora Titular da UESB. ${ }^{5}$ Cirugião-Dentista. Professor Adjunto da UESB. ${ }^{6}$ Cirurgiã-Dentista. Professora Adjunto da UESB. 


\section{INTRODUÇÃO}

São conhecidas sete espécies de coronavírus que infectam seres humanos e a espécie recentemente descoberta (SARS-CoV-2) possui semelhança com $\mathrm{o}$ da síndrome respiratória aguda grave (SARS-CoV), responsável por surtos ocorridos em 2002 e 2003 em Guangdong, província da China. A doença causada pelo SARS-CoV-2 denomina-se "Coronavirus Disease 2019" ou, mais simplesmente, "COVID-19"(1).

A infecção pelo SARS-CoV-2 tem sintomatologia variável, em geral acarretando uma gripe intensa (febre, tosse seca, dificuldade para respirar, dores de cabeça e no corpo), além de diarreia, perda do paladar, perda do olfato, etc., que, rapidamente, evolui para uma condição semelhante a uma pneumonia, comprometendo seriamente a capacidade respiratória. Apesar de a taxa de mortalidade pela infecção variar entre 2 a $15 \%$, esse novo coronavírus se dissemina muito rapidamente entre as pessoas, sendo os grupos mais suscetíveis a desenvolver a forma grave da doença aqueles compostos por idosos, imunodeprimidos ou pessoas que cursam com comorbidades como diabetes, hipertensão, câncer, asma, entre outras doenças crônicas, embora isso não seja uma regra ${ }^{(2-4)}$.

Em 11 de março de 2020, a Organização Mundial da Saúde (OMS) declarou estar em curso uma pandemia causada por esse vírus, a qual teve início em Wuhan, China, no final do mês de dezembro de 2019, chegando ao Brasil em fevereiro de 2020. Os dois primeiros estados brasileiros a apresentarem a contaminação pelo vírus foram São Paulo, em 26 de fevereiro, seguido do Rio de Janeiro, em 5 de março. Nessa data, em São Paulo já existiam 13 casos confirmados e em meados desse mês foi registrada a primeira morte, um homem de 62 anos, com diabetes e hipertensão ${ }^{(2,5)}$.

A partir de então, medidas de distanciamento e isolamento social foram introduzidas, em diferentes momentos, pelos estados e municípios brasileiros, a exemplo de suspensão de aulas; fechamento de órgãos públicos, lojas comerciais, entre outros ${ }^{(5-7)}$. Com isso, a orientação era de que os indivíduos ficassem em suas respectivas casas, motivo pelo qual uma grande parcela da população foi liberada do trabalho presencial, realizando tão somente 0 remoto - com exceção dos profissionais que exercem funções tidas como essenciais, a exemplo dos profissionais de saúde, bombeiros, pessoal de higienização hospitalar, garis, policiais, dentre outros. No intuito de controlar o contágio da infecção, começou-se a exigir que as pessoas acometidas ou suspeitas de contaminação pelo SARS-CoV-2, bem como seus familiares, ficassem em quarentena.

Considerando a estimativa de que $20 \%$ da população de infectados necessitarão de internação hospitalar e, desses, $5 \%$ de suporte ventilatório em unidade de terapia intensiva (UTI), essa contaminação não pode acontecer de forma desordenada, uma vez que isso geraria um caos no sistema de saúde e, consequentemente, um número elevado de óbitos. Por isso, é importante manter a curva de contágio achatada, uma vez que esta revela que a infecção está acontecendo de forma lenta e gradual como consequência dos resultados positivos do cumprimento adequado do distanciamento, do isolamento social e da quarentena ${ }^{(5,8-9)}$.

Sendo os termos "distanciamento", "isolamento social" e "quarentena", bastante utilizados de forma confusa, na atualidade, questiona-se: qual o real significado de cada um deles? Por que motivo esses termos passaram a compor o cotidiano dos brasileiros e das pessoas de todas as partes do mundo, a ponto de serem usados em grande escala nos discursos verbais ou escritos de repórteres, políticos, profissionais da saúde e, até mesmo, das pessoas comuns? De que forma essas medidas contribuem para conter esse vírus que causa tanto medo e ansiedade na população mundial? Seriam essas medidas de fato as únicas soluções para esse problema?

$\mathrm{Na}$ tentativa de encontrar algumas respostas para essas indagações, buscou-se, por meio deste estudo, refletir sobre o distanciamento, isolamento social e quarentena, como medidas de prevenção da infecção em massa pelo SARS-CoV-2, vírus responsável pela COVID-19, na perspectiva de tornar claro o significado e a diferença entre cada uma dessas medidas preventivas, reforçar a importância de sua utilização, neste momento, de pandemia, assim como trazer à tona questões implícitas ou explicitas relacionadas a essa determinação de ficar em casa e manter as pessoas distantes umas das outras para evitar o risco de contrair a doença e contribuir para a sua propagação, o que se espera alcançar a partir das reflexões apresentadas no item resultados e discussão. 


\section{MÉTODOS}

Trata-se de um ensaio teórico reflexivo e, por isso, assemelha-se a estudos de natureza qualitativa, tendo em vista que as reflexões além de serem oriundas da introspecção dos autores se encontram entrelaçadas e reforçadas com as ideias apresentadas por outros estudiosos da temática, identificadas a partir de um levantamento bibliográfico.

Destaca-se que tal levantamento bibliográfico online incluiu treze artigos, nos idiomas português e inglês, disponíveis no Google Acadêmico e na PUBMED/MEDLINE; uma nota técnica, duas recomendações em formato de livro e uma cartilha educativa disponíveis no Google Acadêmico, além de textos publicados em um site oficial e dois jornais online, todos publicados em 2020 e apresentados no item das referências. Ressalta-se ter sido feita também, sem sucesso, uma busca cuidadosa de artigos nas bases de dados constantes no Portal da BVS, revelando, assim, a escassa produção científica sobre o assunto, em abril/2020, período em que se realizou a captura da maior parte do material científico utilizado na elaboração desse artigo, a qual se estendeu até o mês de Junho.

O material bibliográfico foi selecionado a partir da utilização das palavras-chave em português "COVID-19", "isolamento social", "distanciamento social", "quarentena", bem como em inglês: "social isolation", "coronavirus disease", "quarantine" e suas combinações, sem filtros. Ao todo, foram selecionados quarenta e cinco artigos científicos, dos quais trinta e dois não abordavam especificamente a temática estudada e sim aspectos gerais da COVID-19.

Mediante leitura cuidadosa e crítica do material bibliográfico selecionado, iniciou-se a escrita da parte introdutória do estudo, com elaboração das questões norteadoras e o objetivo a ser alcançado ao final do texto teórico reflexivo.

Feito isso, passou-se à escrita da etapa dos resultados e discussão, em que ao tempo que se discorria de forma reflexiva sobre distanciamento, isolamento social e quarentena como medidas preventivas da contaminação pelo novo coronavírus e suas nuances, buscou-se responder às indagações inicialmente apresentadas.

\section{RESULTADOS E DISCUSSÃO}

Diferentemente do isolamento realizado em hospitais, que corresponde à separação espacial das pessoas internadas com doenças transmissíveis, daquelas internadas por outras doenças com o objetivo de protegê-las da infecção ${ }^{(7)}$, o isolamento social é uma medida em que as pessoas são orientadas a não saírem ou saírem pelo tempo estritamente necessário de suas casas, a fim de tentar impedir a propagação de um vírus pelo contato entre indivíduos infectados e não infectados que circulam, normalmente, pelos ambientes públicos $\mathrm{e}$ residências de amigos e parentes.

Por sua vez, esse isolamento social difere também da quarentena, uma condição determinada àquelas pessoas com sintomas da doença à espera da confirmação por testes e pessoas testadas positivamente assintomáticas ou com sintomas leves, além daquelas que tiveram contato direto com essas pessoas, as quais devem, obrigatoriamente, ficar confinadas em suas casas, sem sair, em hipótese alguma, por um período de, no mínimo, quatorze dias (em se tratando da COVID-19), tempo necessário para superar a transmissão viral ${ }^{(2)}$. Acrescenta-se que caso as pessoas assintomáticas em quarentena venham a apresentar sintomas da doença, deverá iniciar-se uma nova contagem de quatorze dias a partir de então ${ }^{(8)}$. Salienta-se que os sintomas da doença normalmente começam a se revelar a partir do quinto dia após a infecção ${ }^{(7)}$.

É importante destacar que ambos, isolamento social e quarentena, precisam ser aplicados associados ao distanciamento social, medida preventiva em que as pessoas devem passar a manter a distância mínima de um metro e meio entre elas e evitar aglomerações ${ }^{(2)}$. Isso, normalmente, ocorre sob orientação do poder público que, preocupado com o risco de infecção em massa, lança mão dessa medida preventiva que separa as pessoas e tenta interromper ou dificultar a transmissão do vírus, uma vez que, por ser uma doença transmitida por gotículas respiratórias, requer distanciamento entre as pessoas. Tal medida torna-se bastante útil em locais em que a transmissão comunitária já tenha se instalado, quando não existe clareza das ligações entre os casos e ainda quando as restrições impostas às pessoas comprovadamente expostas são insuficientes para impedir que ocorra a transmissão ${ }^{(7)}$.

Embora essas três medidas sejam de extrema importância para conter a rápida transmissão da COVID-19, jamais teriam efetividade, se outras não fossem adotadas de modo consciente e adequadas pela população, 
como a lavagem frequente das mãos com água e sabão; uso de máscaras de tecido ao sair de casa; não tocar olhos, nariz ou boca com as mãos, protegendo-se com a dobra do cotovelo ao tossir ou espirrar; não cumprimentar com beijos, abraços ou aperto de mãos; não compartilhar objetos em uso como copos, talheres, canudos, etc.; utilizar álcool a $70 \%$ nas mãos e limpeza de celulares, brinquedos, chaves, controles remotos, etc.; manter o domicílio ventilado e limpo com solução de hipoclorito; etc. ${ }^{(3,8)}$. Ressalta-se a relevância dessas medidas, entretanto faz-se necessário atentar para o fato de que nessa guerra viral as pessoas não devam ser vistas como inimigos biológicos ${ }^{(4)}$.

Ainda sobre $\mathrm{o}$ isolamento social, tem-se que quando este é cumprido apenas pelos ditos grupos de risco (pessoas acima de 60 anos, com diabetes, hipertensão, entre outras comorbidades) é compreendido como isolamento vertical e que quando envolve todas as pessoas independentemente de estarem ou não em situação de risco, exatamente como foi adotado pelo Brasil e pela maioria dos países do mundo, passa a ser chamado isolamento horizontal ${ }^{(10)}$.

Esses dois tipos de isolamento apresentam vantagens e desvantagens. No vertical, a economia continua ativa e sofrendo substancialmente menos, no entanto, o idoso ou a pessoa com comorbidades morando com outras pessoas que circulariam normalmente pelas ruas estariam muito mais propensas à infecção. Já, o horizontal exige que todos os membros da família fiquem isolados dentro de seus lares, oferece maior proteção aos grupos de risco, porém acarreta muitos problemas econômicos ${ }^{(10)}$. 0 Brasil, inicialmente, optou por esse tipo de isolamento, ou seja, pelas vidas humanas e não pelo interesse econômico, embora se saiba que como consequência haverá muito desemprego, declaração de falência de várias empresas e uma dívida externa bem maior do que a previamente existente, por esse motivo, no decorrer do tempo notou-se uma flexibilização do isolamento com consequente reabertura do comércio em diversos estados.

Assim, a escolha pelo isolamento horizontal adotada pelo Ministério da Saúde, em concordância com a OMS, a qual não agradou ao Presidente da República, em razão de sua preocupação, unicamente, com os rumos da economia, tem se mostrado bastante efetiva na redução da velocidade da disseminação da infecção e do adoecimento simultâneo de várias pessoas. Além disso, conseguiu frear a mortalidade pela COVID-19, muito embora a limitada capacidade dos serviços de saúde de vários estados brasileiros revelem superlotação, indisponibilidade de vagas em UTI e dificuldades de acesso aos respiradores artificiais necessários para o tratamento da forma mais grave da doença - a exemplo do Amazonas, Pará, Rio de Janeiro e Pernambuco, que, no final do mês de abril/2020, apresentavam uma taxa de ocupação de UTI superior a $90 \%{ }^{(11)}$.

Considerando as dimensões continentais e as especificidades regionais, reafirma-se que, atualmente, no Brasil já se observa a flexibilização desse isolamento, com reabertura de inúmeros setores em várias cidades, respeitando-se a autonomia dos estados, as dinâmicas sociais e os aspectos epidemiológicos (renda, escolaridade, idade e sexo) desse grande mal que assola o país, podendo ocorrer fechamento gradativo do comércio ou, até mesmo, culminar no bloqueio total (lockdown), na medida em que elevados índices de pessoas com a COVID-19 voltem a acontecer, com consequente aumento do número de internações em UTI ${ }^{(12)}$. Ainda há que se considerar a existência de pessoas que violam o isolamento não dimensionando as consequências graves para si e para outrens ${ }^{(13)}$.

Para além dessas questões, percebe-se que o isolamento social na sua horizontalidade tem muitas outras nuances que não apenas estas ora descritas. Traz, em si, aspectos de natureza emocional, psicológica, biológica, social, cultural, política e até mesmo espiritual que serão aqui abordadas ainda que de forma superficial, dado a sua importância, uma vez que, ao serem desconsideradas, perde-se a visão holística desses seres humanos confinados dentro de suas próprias casas $^{(14)}$.

Especialmente, no Brasil, onde o aperto de mão, o beijo e o abraço são culturalmente reconhecidos como formas carinhosas das pessoas se cumprimentarem a cada encontro, praticar o distanciamento, o isolamento e a quarentena, se torna algo muito difícil. Mais de seis meses já se passaram, desde o momento em que essas medidas preventivas foram adotadas em função da pandemia ter chegado ao país e, certamente, todos anseiam pelo retorno aos encontros calorosos; pelo isolamento opcional; pelo jogo de aproximação e distanciamento que a sociabilidade normal oferece, enfim, que a vida 
em sociedade, com todas as suas adversidades e contradições, possa ser por eles comemorada ${ }^{(4)}$.

No plano psicoemocional, há de se considerar que sentimentos negativos como medo, tristeza, desânimo, estresse, ansiedade, insônia, entre outros, têm sido uma realidade na vida de muitas pessoas que estão cumprindo o distanciamento e o isolamento social ou a quarentena, causados, certamente, por um burburinho de notícias que revelam a todo instante o aumento do número de mortes e de infecção pelo SARS-CoV-2; a ampliação do número de covas em cemitérios; o aumento do número de casos de contaminação, incluindo de profissionais da saúde; a falta de respiradores e vagas em UTI; o desemprego, a redução de salários, a possibilidade de empresas decretarem falência; os gastos públicos com a construção de hospitais de campanha e as compras de equipamentos e materiais hospitalares, evidenciando um obscuro cenário econômico para o país ${ }^{(14-15)}$.

Certamente, isso tudo tem contribuído para dificultar "a formulação de juízos ponderados sobre os riscos reais colocados pela crise do coronavírus", visto que as emoções tanto podem salvar vidas quanto podem embaralhar as cartas do jogo, deixando as pessoas incapacitadas de enxergar com clareza a realidade, ou melhor, ficar sem saber como jogar ${ }^{(16)}$. Estas e outras informações têm chegado muito rapidamente nos lares, por meio da televisão e das redes sociais (WhatsApp, Instagram, Facebook, etc.), responsáveis por não deixar que as pessoas confinadas se esqueçam dessa triste realidade que a população mundial está vivenciando - e que sequer tem uma data definida para acabar, até porque se fala muito na possibilidade da reinfecção e da perspectiva de que uma crise econômica maior possa se instalar como consequência dessa pandemia.

Logo, nunca, o Estado foi tão necessário. "Nunca precisamos tanto de um serviço público de qualidade que chegue a todos!"(17), assim como de políticas públicas capazes de socorrer às pessoas mais vulneráveis, aquelas mais suscetíveis à infecção pelo SARS-CoV-2, por possuírem desvantagens de mobilidade social e não terem alcançado "patamares mais elevados de qualidade de vida em função de sua cidadania fragilizada". Isso significa dizer que, certamente, haverá um maior número de infectados e de óbitos nos locais onde o saneamento básico é precário ou inexistente, onde falta água nas torneiras e muitas pessoas, por não terem como sobreviver isolados dentro das suas casas, terão que "arriscar a descumprir o isolamento social para garantir algum sustento para a família"(2).

Nessa perspectiva, torna-se mais que necessária a ajuda financeira que o governo, de forma bastante confusa, propôs para os menos favorecidos, para aqueles que perderam o emprego ou a oportunidade de trabalhar ainda que de maneira informal, ou seja, para aqueles que foram subtraídos do pouco que ainda tinham pela crise da COVID-19. É notório também que esse desarranjo burocrático possa estar contribuindo para que a infecção se dissemine ainda mais, uma vez que as pessoas terminaram por se aglomerar em filas quilométricas na porta da Receita Federal, de agências dos correios, agências bancárias e casas lotéricas para ter acesso a essa ajuda governamental que, provavelmente, não irá suprir sequer o mínimo necessário para a "sobrevivência" de várias famílias em meio a essa pandemia ${ }^{(18-19)}$.

Desse modo, compreende-se que estar em isolamento social pela COVID-19 envolve muitas questões que as pessoas jamais imaginariam vivenciar um dia, principalmente aquelas que tinham uma vida agitada e que pouco tempo, ou quase nenhum, ficavam dentro de suas casas, seja pela hiperatividade, pela fuga da realidade ou a necessidade de trabalhar, estudar, divertirse, visitar familiares, amigos, etc. De uma hora para a outra, essas pessoas tiveram que encarar a rotina, a ociosidade, a saudade dos familiares e amigos, o barulho das crianças, a impossibilidade de ir ao templo religioso, a violência ou os conflitos familiares, pela necessidade de um convívio forçado, pelo uso do álcool ou outras drogas ou pela falta de condições financeiras para suprir as necessidades básicas da família, entre outros.

Partindo do entendimento de que uma mente sã reflete um corpo são, enquanto que, do mesmo modo, uma mente doente reflete um corpo doente, torna-se possível afirmar que o corpo biológico de muitas pessoas está também sofrendo as consequências do tão necessário isolamento social, considerando a possibilidade de que as mesmas venham a desenvolver sintomas físicos, tais como picos hipertensivos, taquicardia, cansaço físico, dores diversas, entre outros, pelo simples fato de estarem confinadas dentro de suas próprias casas.

Outras implicações ocorrem diante dessa situação. A primeira é o medo que muitas 
pessoas não acometidas pela COVID-19 têm de saírem de suas casas para buscar assistência à saúde e contraírem o vírus. A segunda é pela própria dificuldade com que esbarram ao tentar marcar consultas médicas, tratamentos fisioterápicos ou exames complementares e/ou diagnósticos, especialmente quando invasivos, dado que muitos profissionais autônomos, clínicas ou hospitais não estão realizando atendimentos ou procedimentos e aqueles que os realizam o fazem com número de vagas reduzido, pois tiveram que reorganizar o serviço por horário agendado, a fim de evitar aglomerações e dispor de tempo para, entre cada atendimento, realizarem medidas de antissepsia e assepsia do local e dos materiais utilizados, respectivamente.

Isso remete à reflexão também de que, ao término dessa pandemia, poderá existir uma demanda reprimida de pessoas necessitando de assistência à saúde, por terem retardado a realização dos seus exames anuais de rotina ou por estarem apresentando complicações decorrentes de doenças crônicas prévias ou adquiridas, durante o período em que se mantiveram em isolamento social, visto que, em razão do medo de contraírem o vírus, não buscaram atendimento ou simplesmente não conseguiram agendamento.

Como estratégias de enfrentamento e alívio dos sinais e sintomas oriundos desses sentimentos negativos e das adversidades existenciais sugere-se que as pessoas em isolamento busquem se envolver com as atividades domésticas, mantenham diálogos por meio das redes sociais, evitem assistir muitas notícias de jornais, façam leituras interessantes, assistam a filmes, ouçam músicas, façam atividades físicas, façam meditações, busquem cultivar sua fé e espiritualidade a partir de orações ou mensagens, utilizando inclusive recursos virtuais.

Ficar em casa diante de uma pandemia se concretiza como um ato político. Portanto, as pessoas devem aproveitar essa oportunidade também para amar mais, conviver mais, fortalecer laços, desenvolver habilidades domésticas, culinárias, cuidar de forma mais próxima dos filhos, enfim, desenvolver atividades que venham a agradar ao seu ânimo e melhorar a sua qualidade de vida, assim como a daqueles que estão ao seu lado ${ }^{(4)}$.

Desse modo, cumprir simplesmente com o isolamento social não parece ser suficiente para enfrentar a infecção pelo SARS-CoV-2; tal enfrentamento envolve também estar aberto a realizar mudanças no estilo de vida, a fim de que fique mais fácil encarar essa nova e momentânea realidade.

Assim, promover uma nutrição adequada, praticar exercícios físicos, manter bom padrão de sono; limitar o uso de bebidas alcoólicas e de alimentos industrializados são ações que podem ajudar a manter o corpo vigoroso, saudável e com um sistema imunológico mais fortalecido, de maneira a tornar-se cada vez mais resistente à infecção ${ }^{(20)}$. Torna-se possível, então, compreender a grave situação daqueles menos favorecidos que mal têm o que comer, pouco dormem movidos pela preocupação com 0 sustento da casa e o desemprego e, muitas vezes, recorrem ao alcoolismo para fugir dessa realidade.

Nesse sentido, refletir sobre distanciamento, isolamento social e quarentena em tempos de pandemia pela COVID-19 envolve também pensar na solidariedade como uma das principais armas a serem utilizadas no combate contra esse novo coronavírus. Portanto, faz-se necessário criar um caminho a ser trilhado por todos, de modo que as pessoas possam oferecer umas às outras um pouco do muito ou do pouco que têm na perspectiva de que possam se ajudar mutuamente.

Destarte, acredita-se que as pessoas que estão nesse mesmo barco necessitem de algo e que nenhuma delas é tão vazia que não tenha nada a oferecer. Por isso, o isolamento social em toda sua complexidade se configura em apenas uma maneira de como podem contribuir para a superação dessa crise. Outras maneiras também fundamentais envolvem 0 senso de solidariedade, a exemplo de doar bens materiais (dinheiro, cestas básicas, kits de higiene, máscaras), organizar campanhas; oferecer serviço profissional virtual (atendimento psicológico, consulta médica ou outro); não demitir funcionários, mas negociar com eles, etc.

Aliado a todas essas atitudes, torna-se imprescindível que, nesse momento tão turbulento, as pessoas doem afetos (carinho, amor, atenção), façam orações, ofereçam palavras de conforto, entre outros, não apenas para os que estão próximos, mas também para aqueles que, mesmo distantes geograficamente, a tecnologia e as redes sociais se encarregam de colocar face a face, facilitando ainda mais para 
que esta arma tão poderosa, a solidariedade, possa ser praticada por todos.

\section{CONCLUSÃO}

A pandemia pela COVID-19 é, sem dúvida, o principal desafio do século XXI até o momento. Sua alta transmissibilidade associada ao grande potencial de exaurir os recursos da saúde e, em muitos casos, levar as pessoas acometidas à morte torna tal mazela um grave problema de saúde pública.

O controle dessa pandemia envolve também mudanças profundas nas dinâmicas sociais caracterizadas pelo distanciamento, pela limitação das atividades de trabalho e a atenção substancial para medidas de assepsia e antissepsia. A reflexão acerca de tal desordem nos leva, por um lado à compreensão do grande prejuízo à economia mundial, às relações de trabalho e governamentais, mas por outro se mostra como uma grande oportunidade dos estados ressignificarem suas práticas, dos indivíduos se conhecerem melhor, talvez seja inclusive o momento de se reavaliar o que de "fato é importante" na vida dos seres humanos.

Acredita-se que esse cenário tão caótico do distanciamento e isolamento e todo seu impacto devem gerar, na sociedade, a revisão dos seus valores, a melhor compreensão da vida em coletividade, a busca por minimizar as diferenças sociais, para então obter-se maior justiça social entre os indivíduos.

\section{REFERÊNCIAS}

1- Dal Pizzol F, organizador. Recomendações da Associação de Medicina Intensiva Brasileira para a abordagem do COVID-19 em medicina intensiva. São Paulo: AMIB; 2020.

2- Farias HS. O avanço da Covid-19 e o isolamento social como estratégia para redução da vulnerabilidade. Espaço e Econ. Rev Bra Geogr Econ. 2020;9(17):1-10. DOI: 10.4000/espacoeconomia.11357

3- Silva Júnior AF, Souza AA, Monteiro JRS, Silva MCF, organizadores. Conhecendo o COVID-19: Cidadão esclarecido, cidade segura! Altamira/PA: UFPA; 2020.

4- Bittencourt RN. Pandemia, isolamento social e colapso global. Rev Espac Acadêm. 2020 [citado em 25 abr 2020]; 19(221):168-78. Available in: http://periodicos.uem.br/ojs/index.php/EspacoA cademico/article/view/ 52827/751375149744

5- Radis S. Coronavírus: Lições e visões de uma pandemia. RADIS 2020 [citado em 27 abr 2020];
211:5-7. Available

in: https://radis.ensp.fiocruz.br/phocadownload/revi sta/Radis211_web.pdf

6- Moraes RF. Nota Técnica - Medidas legais de incentivo ao distanciamento social: Comparação das políticas de governos estaduais e prefeituras das capitais no Brasil. Brasília: IPEA; 2020.

7- Wilder-Smith A, Freedman DO. Isolation, quarantine, social distancing and community containment: Pivotal role for old-style public health measures in the novel coronavirus (2019nCoV) outbreak. J Travel Med. 2020; 27(2):taaa020. DOI: 10.1093/jtm/taaa020

8- Brasil, Ministério da Saúde. Sobre a doença coronavírus. Brasília: Ministério da Saúde; 2020. Available in: https://coronavirus.saude.gov.br/ sobre-a-doenca\#tratamento

9- Crispim D, Silva MJP, Cedotti W, Camara C, Gomes SA. Comunicação difícil e COVID-19: Recomendações práticas para comunicação e acolhimento em diferentes cenários da pandemia. Belo Horizonte: AMMG; 2020.

10- Gomes FAR. Isolamento horizontal versus isolamento vertical no combate à covid-19. J USP 2020. [citado em 26 abr. 2020]. Available in: https://jornal.usp.br/artigos/isolamentohorizontal-versus-isolamento-vertical-nocombate-a-covid-19/

11- FOLHAPE. Mesmo com novos leitos para Covid-19, UTIs brasileiras têm alta taxa de ocupação. Folha PE 2020. [citado em 03 maio 2020]. Available in: https://www.folhape.com.br/ noticias/noticias/coronavirus/2020/04/29/NWS,1 38759,70,1668,NOTICIAS,2190-MESMO-COMNOVOS-LEITOS-PARA-COVID-UTIS-BRASILEIRASTEM-ALTA-TAXA-OCUPACAO.aspx

12- Bezerra A, Silva CEM, Soares FRG, Silva JAM. Fatores associados ao comportamento da população durante o isolamento social na pandemia de COVID-19. Cienc Saúde Coletiva 2020;25(supl 1):2411-21. DOI: 10.1590/141381232020256.1.10792020

13- Farias JEM, Pilati R. Violating social distancing amid the COVID-19 pandemic: Psychological factors to improve compliance. PsyArXiv Preprints 2020. [citado em 20 jun 2020]. Available in: https://psyarxiv.com/apg9e. doi:10.31234/osf.io/apg9e

14- Banerjee D, Rai M. Social isolation in Covid19: The impact of loneliness. Int J Soc Psychiatry 2020;1-3. DOI: 10.1177/0020764020922269

15- Singhal, T. A review of coronavirus disease2019 (COVID-19). Int J Soc Psychiatry 
2020;87(4):281-6.

DOI:

10.1177/0020764020922269

16- Williges F. As lições emocionais da COVID-19. Estado da Arte 2020. [citado em 30 abr 2020]. Available in:

https://estadodaarte.estadao.com.br/licoesemocionais-covid-19/

17- Ponte CF. O que a pandemia pode nos ensinar? RADIS 2020. [citado em 27 abr 2020]; 211:35 Available in: https://radis.ensp.fiocruz.br/ phocadownload/revista/Radis211_web.pdf

18- Komatsu B K, Menezes NF. Simulações de impactos da COVID-19 e da renda básica emergencial sobre o desemprego, renda, pobreza e desigualdade. Policy Paper 2020. [citado em 20 jun 2020]; 43:1-31. Available in: https://www.insper.edu.br/wp-

content/uploads/2020/04/Policy-Paper-v14.pdf 19- Jesus RS, Santos PP, Sousa TD, Oliveira A, Avelar KES. Os desafios do governo brasileiro para o enfrentamento da pandemia do coronavírus. Rev Augustus 2020 [citado em 20 jun 2020]; 25(51):31-55. Available in: https://revistas.unisuam.edu.br/index.php/revist aaugustus/article/view/556/290

20- Vaz-Fernandes P. Covid-19 e estilo de vida saudável. Universidade Aberta 2020 [citado em $26 \mathrm{abr}$ 2020]; 1-5. Available in: https://repositorioaberto.uab.pt/bitstream/1040 0.2/9591/3/Covid-19_COVID-19\%20e\%20Estilos \%20de\%20Vida\%20Saud\%c3\%a1vel_Paula\%20Va z-Fernandes_CC.pdf

Nota: Não houve financiamento por parte de nenhuma agência de fomento.

Recebido em: 20/05/2020

Aprovado em: 29/06/2020

Endereço de Correspondência:

Departamento de Saúde I. Universidade Estadual do Sudoeste da Bahia/UESB. Avenida José Sobrinho, S/N. Jequiezinho, Jequié-Bahia, Brasil. CEP 45208-409. 